THE COLLEMBOLA OF LEBANON

AND WESTERN SYRIA. PART I.

GENERAL CONSIDERATIONS AND

THE FAMILY ONYCHIURIDAE

By K. Christiansen

Grinnell College, Grinnell, Iowa

The Collembolan fauna of the eastern end of the Mediterranean is still very poorly known. Brown (1926) made the first major contribution by describing twelve species taken by Buxton and Evans in the region of Amara and Baghdad in Iraq. Handschin (1942) recorded all but one of these species from Palestine, and added 26 additional forms. In his recent paper upon the Collembola taken during a speleological expedition in Lebanon, Cassagnau (1951) added 25 new forms to this list. In addition to these major works a number of smaller papers have been published upon new material or further records.

The series of papers, of which this is the first, will constitute a description of over 80 species collected from Lebanon and Western Syria. More than 35 are new to science or new records for the Near East. Collections upon which this study was based were made from over 100 localities including most of the major habitats of the region. Caves were poorly represented, but these have already been extensively investigated by Cassagnau (op . cit.).

\title{
ACKNOWLEDGEMENTS
}

The material described in these papers was collected during my three-year stay at the American University of Beirut, and I wish to thank the staff of that organization for their financial aid and encouragement in the completion of the project. The collecting, handling, and sorting of material was greatly aided by a number of 
students, particularly Mr. Raja Asfour and Mr. Muhammed Salaymeh. I particularly wish to thank Dr. H. Gisin for his helpful comments.

\section{DESCRIPTION OF LOCALITIES}

Lebanon and Western Syria comprise an area of extremely variable topography and ecology. The most prominent physical feature of the area under consideration is the Lebanon Mountain Range. This range reaches its highest peak $(10,131 \mathrm{ft}$.$) in North Central Lebanon and$ gradually decreases in height northward. Between these mountains and the sea is a narrow coastal plain which widens from south to north. In Lebanon a second parallel mountain range, the Anti-Lebanon Mountains, marks the Western border of this country. Between these two ranges lies the central valley of the Bekaa, which continues in the North as the North Syrian Plain. The single common ecological factor is that most of the area is greatly impoverished by almost every conceivable type of land overuse. Many of the mountainous areas are largely denuded of soil due to excessive grazing by goats and the resultant erosion. Most of the valley or plains regions suffer from chronic nitrogen and mineral lack, while most of the desert flora is kept in a condition of abnormal dwarf growth by the excessive grazing of the Bedouin flocks. The few nearly natural regions left are largely limited to the rare forests of the larger mountain peaks of Lebanon, the pine forest of Northern Latakia, and the deeper reaches of the desert. Except for the mountain areas, rainfall is completely seasonal, being limited to the winter months. The rainfall varies from 34 inches in Beirut to less than 3 inches in some regions of the Syrian Desert. In both cases most of the rain falls between November 1st and May 1st, and rain in July or August is unheard of. The effect of this is that the Collembola vary in both abundance and occurrence according to areas and seasons. In the more humid areas Collembola are abundant whereever food material occurs in the rainy season. In drier regions they are very rare in most areas. In all parts of the country numerous refugia exist with year-round mois- 
ture of a sufficiently high level to support a more or less permanent population. Such refugia occur along the banks of rivers, in the moist beds of dry streams, or the edges of ponds and lakes. Most commonly they are found around the borders of the numerous springs of the mountainous regions. In extreme desert regions only a few xerophilic species can be found far from the limits of these refugia. The swamps or lake shore refugia frequently show an impoverishment of collembolan fauna, possibly due to their periodic inundation. Almost all of the Lebanese and Syrian level arable land is under heavy cultivation. Most of the species occurring in such areas are migrants or agriculture-tolerant forms. On the whole the fauna in this region is impoverished, although an occasional wood lot or hedge-row may be quite rich in some forms.

The lower slopes of the Lebanese Mountains are largely covered by small xerophytic brush and a few strands of hardy grass. Wherever enough soil and enterprise remain, terraces are built and fruit, wheat and other crops are grown. A few planted and more or less carefully parked pine forests exist in a few regions, especially in southern Lebanon. All of these habitats have extremely limited collembolan faunas, although a large percentage of indigenous forms occurs. The richest faunas occur in the high Lebanese Mountains. These areas were probably one time entirely forested, with spruce forests in the northern areas, and cedar in the central and southern regions. At the present time only four forests of any size are left, the remainder of the slopes being kept in a barren rock condition with poor herb grass-low shrub covering. The existing forests are: a large spruce forest in the Halba region of northern Lebanon; the Hadeth, Ain Zahlte, and Barouk cedar forests in central and southern Lebanon. All of these forests are growing on limestone substrates mostly on or near mountain peaks. The forest soil consists generally of a thin layer of duff, beneath which is a shallow black or gray humus. Below this layer limestone appears, frequently as bedrock. The forests tend to be open, with undergrowth limited to the edges and cleared central valleys. The spruce forest was largely cut 
cver by the British in 1945 , so that only a few large trees remain. Most of this forest land is now clothed with second growth of small spruces and shrubs. The Hadeth cedars are being heavily but sporadically cut at the pre $\approx$ ent time, but the other two forests have bcen largely uncut for the last twenty years. Most of these forest lands support some fauna in the deeper soil layers, even during the driest seasons.

In addition to the forest regions a large number of steep valleys occur where rain and surface water maintain continuous moist conditions. Such areas usually have a lush mesophytic flora, which is of striking contrast to the barren overgrazed xerophytic vegetation of the surrounding mountains. Such areas have an abundant collembolan fauna and because they are isolated by large stretches of dry, impoverished territory, the fauna of each valley is usually somewhat unique.

A last major habitat type is represented by the Northern Latakian Pine Forest. This large forest is situated directly below the Turkish border and is continuous into Southern Turkey. The area on the whole is similar to the mountain forests of Lebanon except for 1.) the development of a true podsol, and 2.) the existence of isolated patches of beech-oak mesophytic forest. These last areas have probably the richest collembolan faunas of any region of the Near East with many forms being represented from these areas only. These patches of deciduous forest occur apparently only at regions of excessive ground water and remain humid during most of the year. In this, and other respects, these patches of mesophytic woods resemble the isolated humid valleys of the high Lebanon Mountains, but are infinitely richer in fauna, possibly due to their existence in the center of the well populated pine woods area.

General Zoogeographical Considerations

The collembolan fauna of this area belongs to four major distribution groups. In order of their representation in the fauna, these are: 1.) Circum-Mediterranean; 2.) Holarctic-Cosmopolitan; 3.) Xerophytic North African 
and 4.) Central European. In addition to these there are a number of forms of dubious zoogeographical associations. There are a large number of species (as far as is now known) limited to the area. It is no surprise that the great majority of this last group occurs in the relatively untouched forest areas and deep valley mesophytic regions, while the lowland farm areas show a great preponderance of widespread forms. Determining which forms are indigenous and which have been introduced is made utterly impossible by the antiquity of commerce and agriculture in the area, as well as our lack of knowledge concerning distribution mechanisms in Collembola.

\section{SYSTEMATIC PORTION}

Four species of the family Onychiuridae have been previously reported from the region. These are: Onychiurus fimetarius, O. armatus, O. octopunctatus, and Metaphorura bipartita. In the present paper two of the above are again recorded and six additional species are found: Stenaphorura quadrispina, Onychiurus ambulans, and four new species of Onychiurus.

\section{Onychiurus levantinus $n$. sp.}

\section{Plate 7, Figures 5-8}

Description of holotype (female): Color white; body elongate sub-cylindrical with sixth segment strikingly smaller than remainder; antennae with line between third and fourth segments indistinct; sensory organ of third antennal segment with five protective papillae, a pair of slightly curved rods and a pair of knob-covered oval organs; P.A.o. of 35 closely packed simple lobes in the form of a narrow ellipse; integument uniformly granulate, only slightly coarser on dorsal surface of head than remainder of body.

Following the chaetotaxy system developed by Gisin (1952), the holotype has the following formulae: 1st thoracic segment: i3m; abdominal segment two: M SS ' $M$ '; abdominal segment five: $M$ Ss 'M. The relationship between setae $M$ and $S$ of abdominal segment five is $19 / 12$ 
with the anterior border of the anal horns taken as 10 .

The unguis is untoothed with the empodial appendage having a long filiform extension slightly exceeding the apex of the unguis. The anal horns are curved and stout, about as long as the hind unguis. A small but well developed cuticular fold exists in the region of the furcula. Pseudocellar formula: Dorsal surface - 32/022/333420. No pseudocelli seen on ventral surface of animal.

Variation and Discussion. ${ }^{1}$ The number of lobes on the P.A.o. varies from 28 to 36 , with even smaller numbers occurring on obviously immature specimens. The male specimens never display any special ventral organ. The pseudocelli are constant except for a pair of ventrals appearing occasionally on the head. The lateral pseudocelli on the third thoracic segment, and the lateral posterior pair on the fourth segment, are not always clearly visible, but further examinations have led me to believe that this is a matter of technique and that they are always present. The chaetotaxy of the first thoracic segment varies a

${ }^{1}$ Unless otherwise stated, the variation mentioned in each of these sections is that found in normal specimens of apparent sexual maturity.

\section{Explanation of Plate 7}

Figs. 5-8. Onychiurus levantinus n. sp. Fig. 5. Third antennal segment organ paratype (male). Organ length 18 micra. Fig. 6*. Posterior border fifth abdominal segment, specimen from "The Cedars," Lebanon. Side view. Fig. 7. Tergum first thoracic segment, same specimen. Side view. Fig. 8. Posterior margin second abdominal segment, same specimen. Figs. 9-11. Onychiurus butrosi n. sp. Fig. 9. Side view third antennal segment organ, specimen from Hermel, Lebanon. Length of sensory clubs 4 micra. Fig. 10. Ventral view, same organ and specimen. Fig. 11. P.A.o., same individual. Magnification as above. Figs. 12-15. Onychiurus fazii n. sp. Fig. 12. Claw, specimen from Latakia, Syria. External edge unguis 36 micra. Fig. 13. Third antennal segment organ, specimen as above. Organ length 20 micra. Fig. 14. Sensory clubs of third segment organ, another specimen from Latakia. Fig. 15. Sensory clubs as above, specimen from Ain Z'halte, Lebanon.

* Dotted lines in figures 6,7 and 8 represent limits of variation of setae bases in more variable setae. 

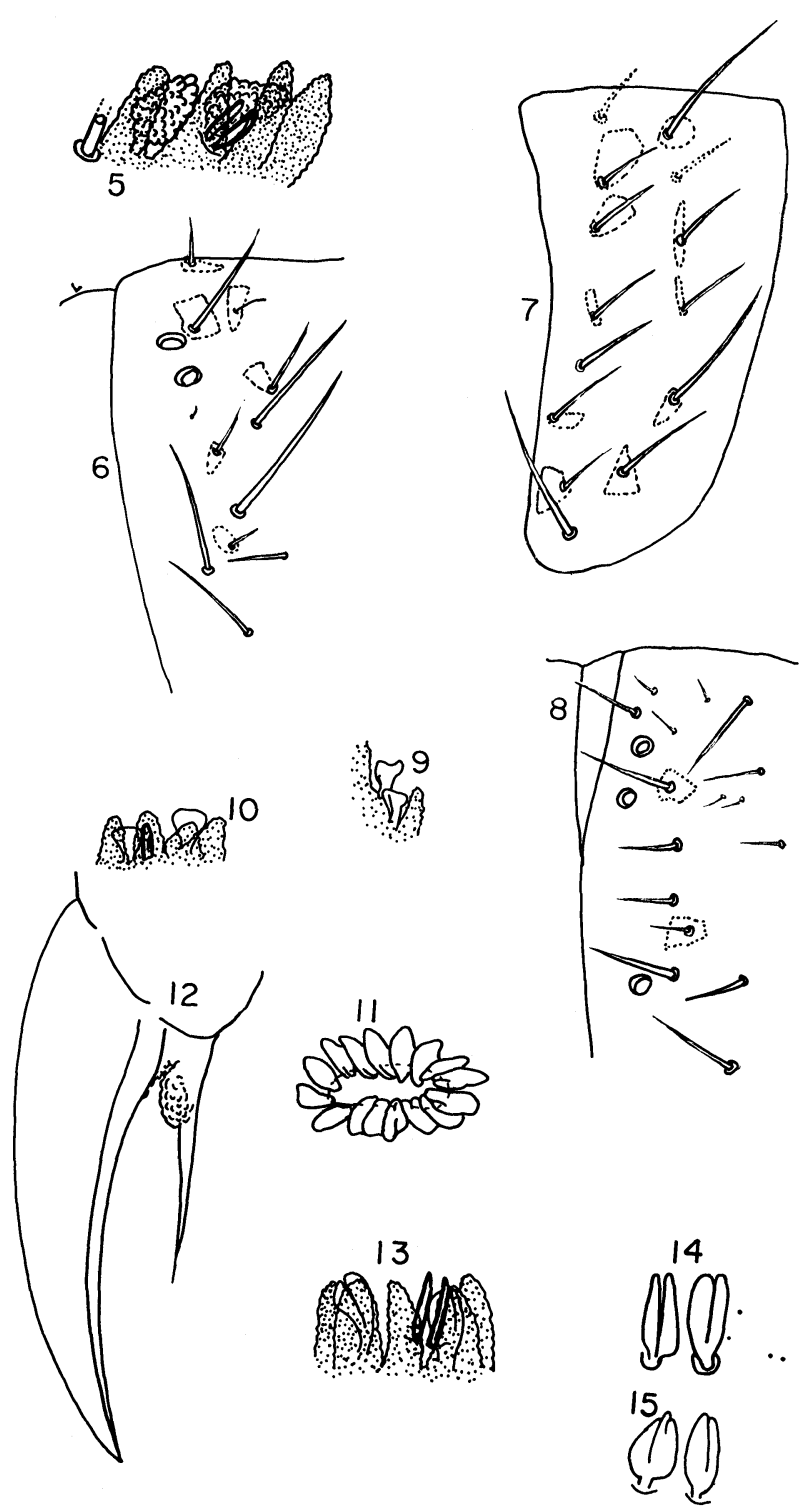

Christiansen - Onychivrus 
great deal. All of the following chaetotaxy formulae are to be found (Gisin, 1952) : ilm, i3m, i2-, and i3-. The formula $\mathrm{i} 3 \mathrm{~m}$ is by far the most common and may be considered typical of the species. The relationship of the $\mathrm{M} / \mathrm{s}$ setae of the fifth abdominal varies from $17 / 10$ to $19 / 12$, with 18/11 being the commonest form.

The species is distinguished from all others of the armatus group by a combination of characters, particularly the presence of 2 pairs of pseudocelli on the posterior borders of the head and fifth abdominal segment, the absence of ventral pseudocelli, and the relationship of $\mathrm{M} / \mathrm{s}$.

Type locality: Ain Z'halte Cedars, Lebanon, X-28-53. Also taken from: Vicinity Becharra Cedars, Lebanon, VII-1-52; "The Cedars," elev. 1900 m., Lebanon; Vicinity Bludane, Syria.

Onychiurus armatus Tullberg

Onychiurus armatus Tullberg, 1869, Akad. Afhandl. Uppsaler. Pp. 1-20.

I have found this species from a single locality: Ain Z'halte Cedars, Lebanon. Cassagnau reports it from six localities in Lebanon, but the localities he reports it from make it appear probable that he is including under this name both armatus and $O$. levantinus.

Onychiurus octopunctatus Tullberg

Onchiurus octopunctatus Tullberg, 1876, Ofver. Kongl. Vet.-Akad. Forhand. $33: 23-42$.

Two specimens of this species were reported from Lebanon by Cassagnau.

Onychiurus butrosi n. sp.

$$
\text { Plate 7, Figures 9-11 }
$$

Description of holotype (male): Color extremely pale yellow; body stout, somewhat swollen posteriorly; last three abdominal segments not clearly separated; head with a number of long, straight or slightly curved setae largely confined to the lateral and posterior portions; first thoracic segment with a single row of setae as described for $O$. 
zschokkei; ${ }^{2}$ fifth and sixth abdominal segments with a number of very long setae prominent on the sixth, where they make a brush-like cluster at the end; anal horns small and similar in structure to small setae; third antennal sense organ with four slender protective papillae, and a single peg-like sensory rod; two large, flat sensory clubs, irregularly clavate in dorsal (or ventral) view, but slender capitate structures when seen laterally; fourth antennal segment with a small but definite bulb in a subapical pit and 16 large, curved, slightly blunted setae present on the apical part; no ventral organ present; P.A.o. of 18 irregular tubercles arranged in a rough ellipse; claw simple, untoothed with empodial appendage acuminate and reaching about half distance from base to apex of unguis, pseudocellar formula: dorsal surface - 32/122/ 223320 , ventral surface $-1 / 000 / 001100$.

Variation and Discussion. This species is very similar to O. zschokke $i$ in general structure. The chaetotaxy, P.A.o., and general appearance are all similar. It differs in the structure of the third antennal segment sense organ, and the range of variation in the number of lobes of the P.A.o. In the present species this ranges from 14-20, whereas in zschokkei it varies from 20-30. There appears to be a great deal of variation in the pseudocelli of butrosi; however, it is difficult to determine how much of this is a matter of technical difficulties and how much is real variation. The commonest condition appears to be that described for the holotype. The second thoracic segment may have two and the second abdominal segment one pseudocellus. Abdominal segments three and four occasionally have two pseudocelli on each side of each segment.

Type locality: "The Cedars," Lebanon, elev. $1900 \mathrm{~m}$. Also taken from: American University Campus, Beirut, Lebanon, V-29-52; Barouk Cedars, Lebanon, VI-14-53; Vicinity Bludane, Syria.

\section{Onychiurus fimetarius Linné}

Onychiurus fimetarius Linné, 1766, Systema Naturae, ed. 12. 1(2):1013.

Cassagnau reported this species from five localities.

\footnotetext{
${ }^{2}$ Extracts from a paper upon $O$. zscokkei by $\mathrm{H}$. Gisin now in press.
} 
I did not recover the species even in collections from the same locality. This difference might be due to collection techniques, as I never used the earth washing method, but it appears more likely that there is a difference of identification. In any case the occurrence of this species, as separate from the new forms described in this paper, must be tentative.

\section{Onychiurus archivari n. sp.}

\section{Plate 8 , Figures 16-25}

Description of holotype (female): Color white; setae on ventral surface of second through fourth abdominal segments very small and numerous; a single large seta on the lateral margin of each thoracic tergite; large setae of dorsal surface becoming larger and more numerous rearward; on fifth and sixth abdominal segments they form double transverse rows; anal horns well developed, about half as long as unguis, slightly curved and situated on very small integumentary rings which have non-confluent bases; pseudocelli equipped with small closing teeth; third antennal sense organ of four slender protective papillae, a pair of slender curved rods, and two smooth pine-tree-shaped sensory knobs; a single small bilobed knob appears on the fourth antennal segment in a deep pit slightly below the apex; ventral surface of fourth antennal segment equipped with numerous small smooth

\section{Explanation of Plate 8}

Onychiurus archivari n. sp. Fig. 16. P.A.o., specimen from Ain Z'halte Cedars, Lebanon. Organ length 28 micra. Fig. 17. Anal spine of same specimen. Length 20 micra. Fig. 18. Anal spines paratype. Length 19 micra. Fig. 19. Third antennal segment organ, specimen from Ain Z'halte Cedars, Lebanon. Organ length 22 micra. Fig. 20. Third antennal segment organ of paratype. Magnification as above. Fig. 21. Third antennal segment sense organ another paratype. Fig. 22. Left hind claw holotype. External edge unguis 49 micra. Fig. 23. Male genital plate paratype. Organ length 38 micra. Fig. 24. Dorsal surface of head of paratype. Fig. 25. Right antennal base, specimen from Ain Z'halte Cedars, Lebanon. 

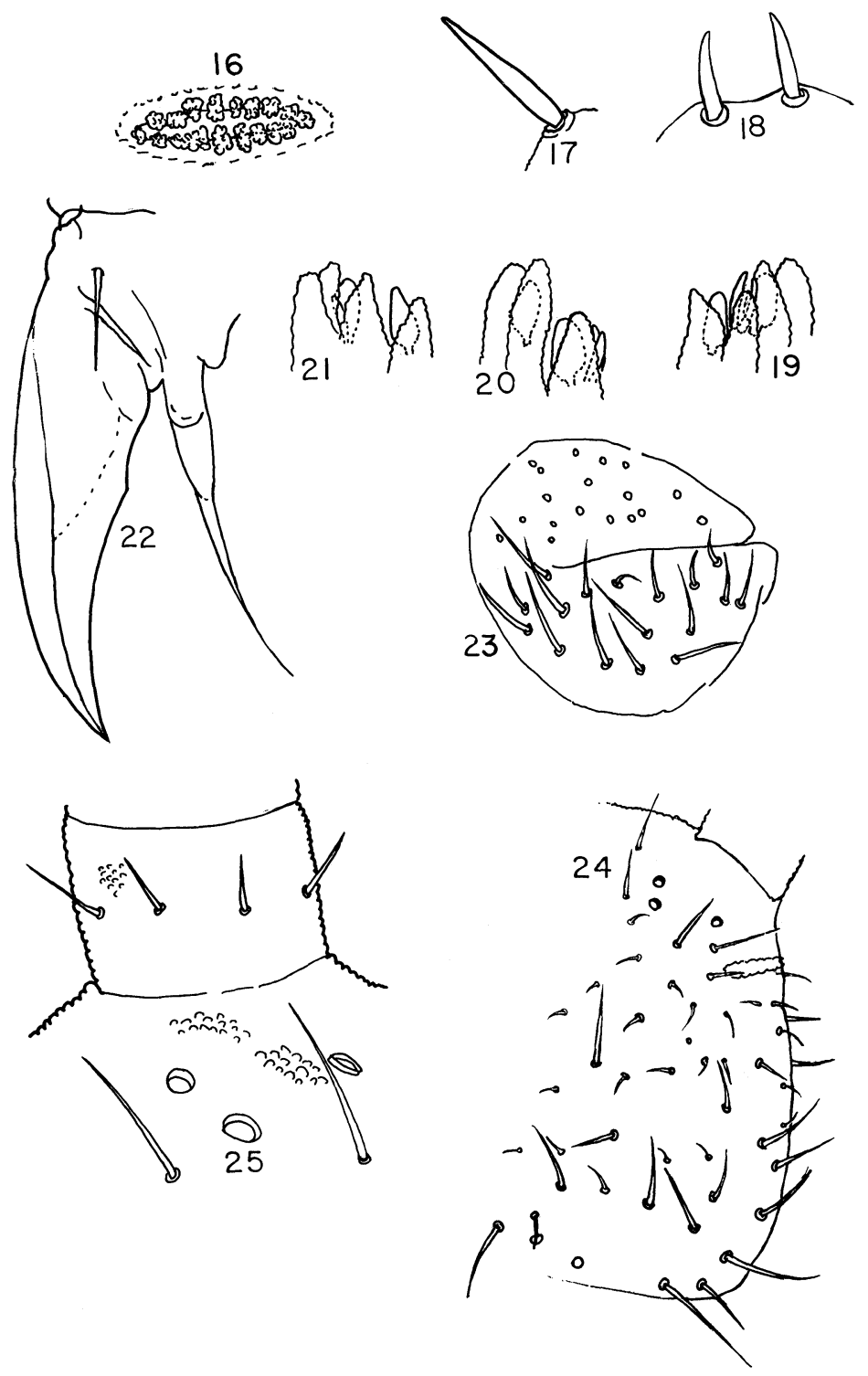

Christiansen - Onychiurus 
setae, dorsal surface with many long curved ones, those near the apex somewhat heavier and blunter than the remainder; P.A.o. of 14 complex lobed papillae, arranged in an elongate ellipse; claw untoothed, apical filament of gradually acuminate empodial appendage exceeding level of apex of unguis; integument of antennal bases not clearly distinguishable from that of remainder of head; no furcula remnant visible; pseudocellar formula: $32 / 123 / 333330$; no ventral pseudocelli seen; bases of coxae each with a pair of pseudocelli.

Variation and Discussion. The sensory knobs of the third antennal sense organ vary from more or less triangular as described to an almost circular shape. Most specimens have triangular or oval organs or some compromise between these. The number of pseudocelli varies a good deal. The condition described for the holotype is that found on the majority of adult specimens. The first three abdominal segments may have four or, rarely, five pseudocelli. The coxal bases often appear to have a single pseudocellus, but this may be due to the structure of this organ which tends to hide the pseudocelli in integumentary folds. The number of lobes in the P.A.o. varies from 12 to 18.

This species is a member of the ambulans group and is unique in its absence of ventral pseudocelli. Among the species of this group it appears to be most closely related to boldorii and stillicidii, but differs from both of these by the complete absence of a ventral organ on the adult males, in addition to the distribution of the pseudocelli.

Type locality: Barouk Cedars, Lebanon, VI-14-53, elev. $1700 \mathrm{~m}$. Also taken from: Hadeth Cedars, Lebanon, elev. 1700 m., VII-19-53; Ain Z'halte Cedars, Lebaron.

Onychiurus fazii $n$. sp.

Text-figure 1; Plate 7, Figures 12-15

Description of holotype (male) : Color pale yellow; body stout, bluntly rounded and expanded posteriorly. For chaetotaxy see figures. Anal horns absent; third antennal segment sense organ with four granulate protective papillae, a pair of subcylindrical rods, and a pair of flat- 
tened, ovoid, bifid, sensory knobs; P.A.o. with 16 complex lobed sensory papillae arranged in a narrow ellipse; tubercles of the integument very coarse on head and dorsal surface of body, smaller on antennae with line of demarcation sharp; unguis untoothed; empodial appendage expanded basally but without lamella; filamentous extension of appendage, reaching three-quarters distance from base to apex of unguis; fourth antennal segment without unusually thick setae, but with well developed subapical bulb in a deep pit; pseudocellar formula: dorsal surface - 32/123/333330, ventral surface-0/000/111100; each leg base has a pair of pseudocelli; no clear ventral organ (see discussion below).

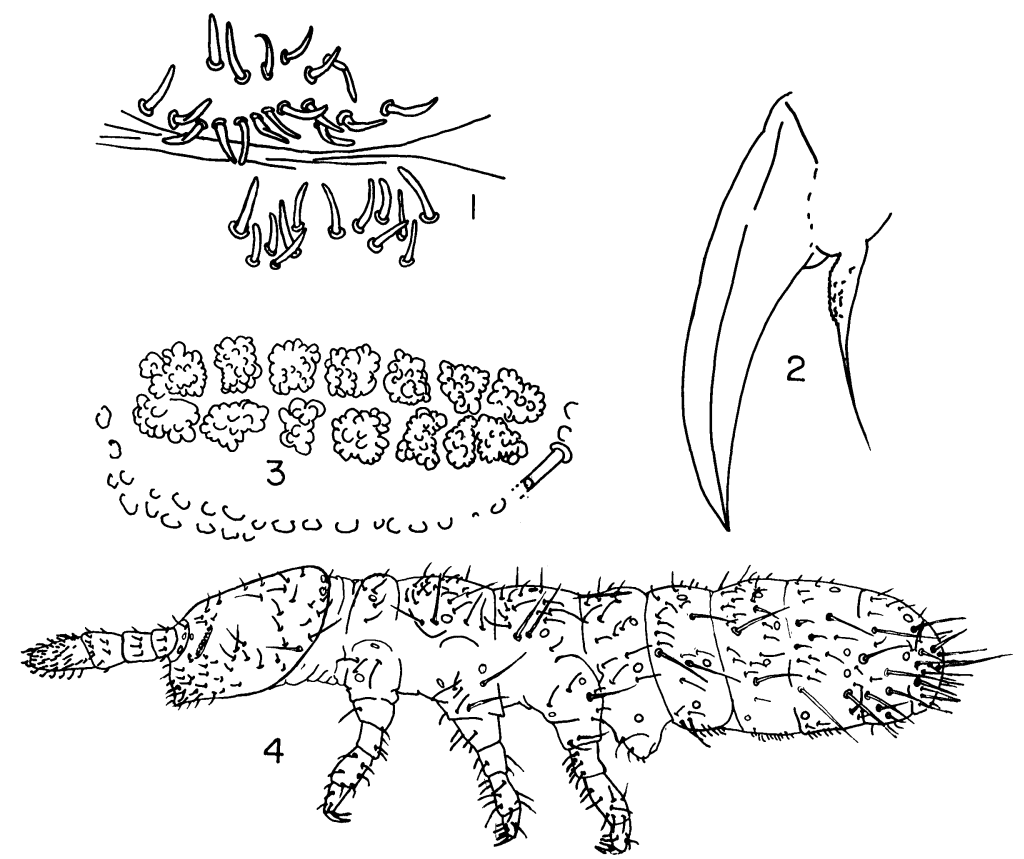

Text-figure 1. Characteristic structures of Onychiurus fazii n. sp. 1. Male ventral organ, specimen from vic. Sidon, Lebanon. 2. Hind unguis, specimen from Ain Z'halte Cedars, Lebanon, external edge $\mathbf{5 8}$ micra. 3. P.A.o., same specimen, length organ 60 micra. 4. Habitus paratype, length $2.4 \mathrm{~mm}$. 
Variation and Discussion. This species is one of the most variable known in the genus. At one point I decided that it actually represented two separate species, but further studies showed that the various differential characteristics varied individually from population to population making it impossible to separate out two clear entities. Unfortunately, the samples available at present are small, and any final settlement of the taxonomic status of the several variations seen in this species must await careful analysis of further collections.

The most striking variation concerns the male ventral organ. Some populations lack this entirely even in adult specimens, while other populations have a well developed ventral organ (see figure) consisting of a number of finger-like setae situated around the border of the second and third abdominal segments. In some populations, apparently, adult males exist both with and without this organ. The ventral pseudocelli may be entirely absent, while in a few forms a single pair of ventrals occur on the head. The dorsal surface of the third and fourth abdominal segments may have four pseudocelli, while the leg bases may have only one or one on the first pair and two on the remainder. The apical filament of the empodial appendage may exceed the apex of the unguis or only reach to its middle. The chaetotaxy also varies a great deal, particularly in the posterior parts of the abdomen. It is quite possible that larger series will show this to be a species complex rather than a single variable form.

Type locality: American University Campus, Beirut, Lebanon, X-53. Also taken from: Chamlane, Lebanon, XII-13-53; Ain Z'halte Cedars, Lebanon, XI-2-53; Latakia, Syria, just below Turkish border, VII-2-53.

Metaphorura bipartita Handschin

Metaphorura bipartita Handschin, 1920, Verh. Naturf. Gesel., Basel. 32:1-37.

The specimens of this species appear to be very typical. Cassagnau found it in two places, Jezzine, 6-XI-51, and Sources de Habani, 22-XI-51. I located it in two other places, $14 \mathrm{~km}$. South of Sidon and Ain Z'halte, Lebanon. 


\section{Stenaphorura quadrispina Börner}

Stenaphorura quadrispına Börner, 1901, Zool. Anz. 24(133):1-15.

The specimens of this form (about 12) all came from a single collection: Ain-Tiffaha (vicinity Quaranita), Lebanon, VII-31-52, elev. $1500 \mathrm{~m}$. They differ from the forms described by Stach by having the anterior horns more than half as long as the posterior pair.

\section{Literature Cited}

Brown, J. M.

1926. Some Collembola from Mesopotamia. Jour. Linn. Soc., London. $36: 201-218$.

Cassagnau, P. and C. Delamare Deboutteville

1951. Mission Henri Coiffait au Liban. Biospecologia LXXV. Arch. Zool. Exp. Gen. 91(4):365-395.

Gisin, H.

1952. Notes sur les Collemboles, avec démembrement des Onychiurus armatus, ambulans et fimetarius auctorum. Mitt. Schweiz. Ent. Ges. $25: 1-22$.

HANDSCHIN, E.

1942. Collembolen aus Palastina, nebst einem Beitrag zur Revision der Gattung Cyphoderus. Rev. Suisse Zool. Geneva, 49(22): 401-450. 

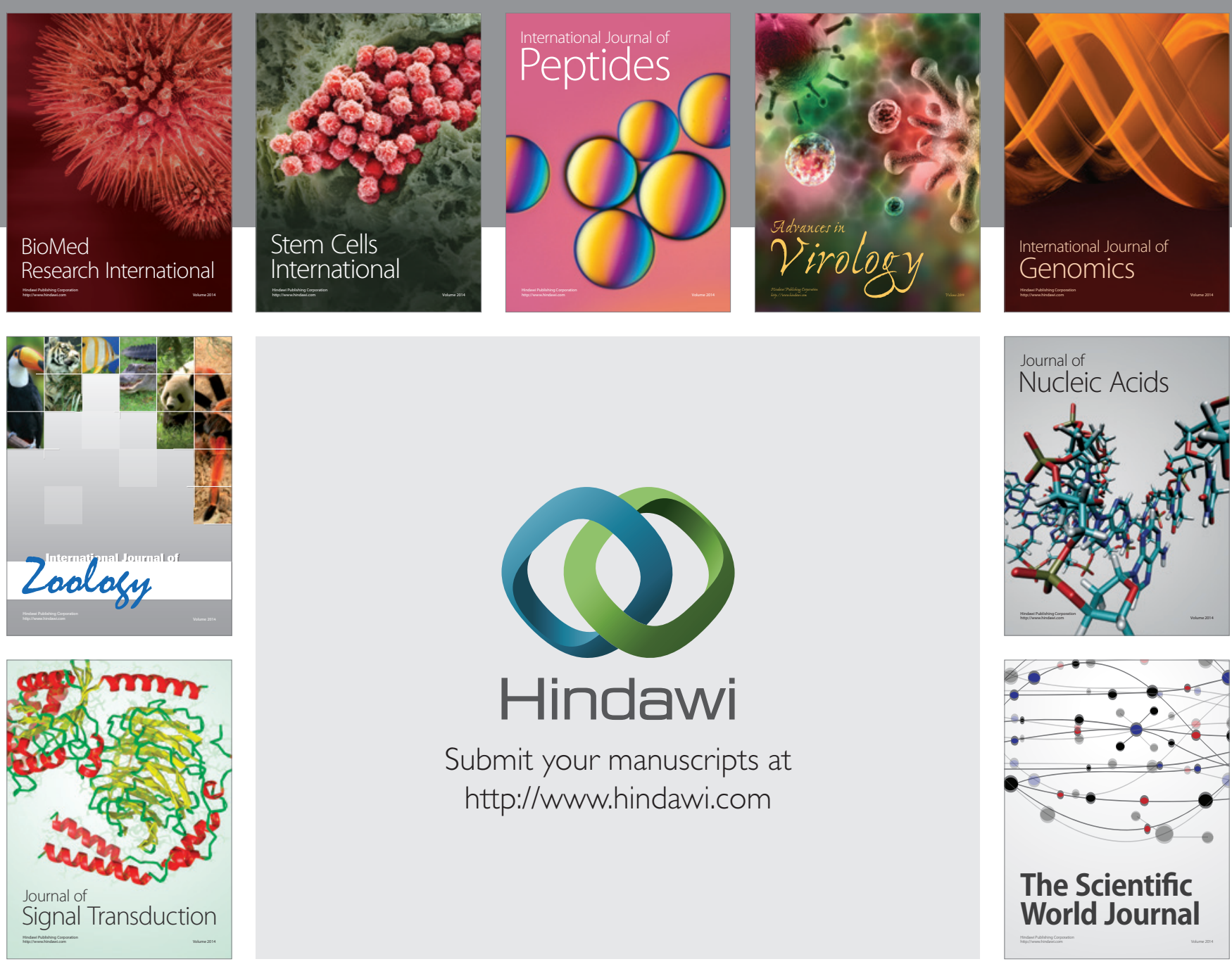

Submit your manuscripts at

http://www.hindawi.com
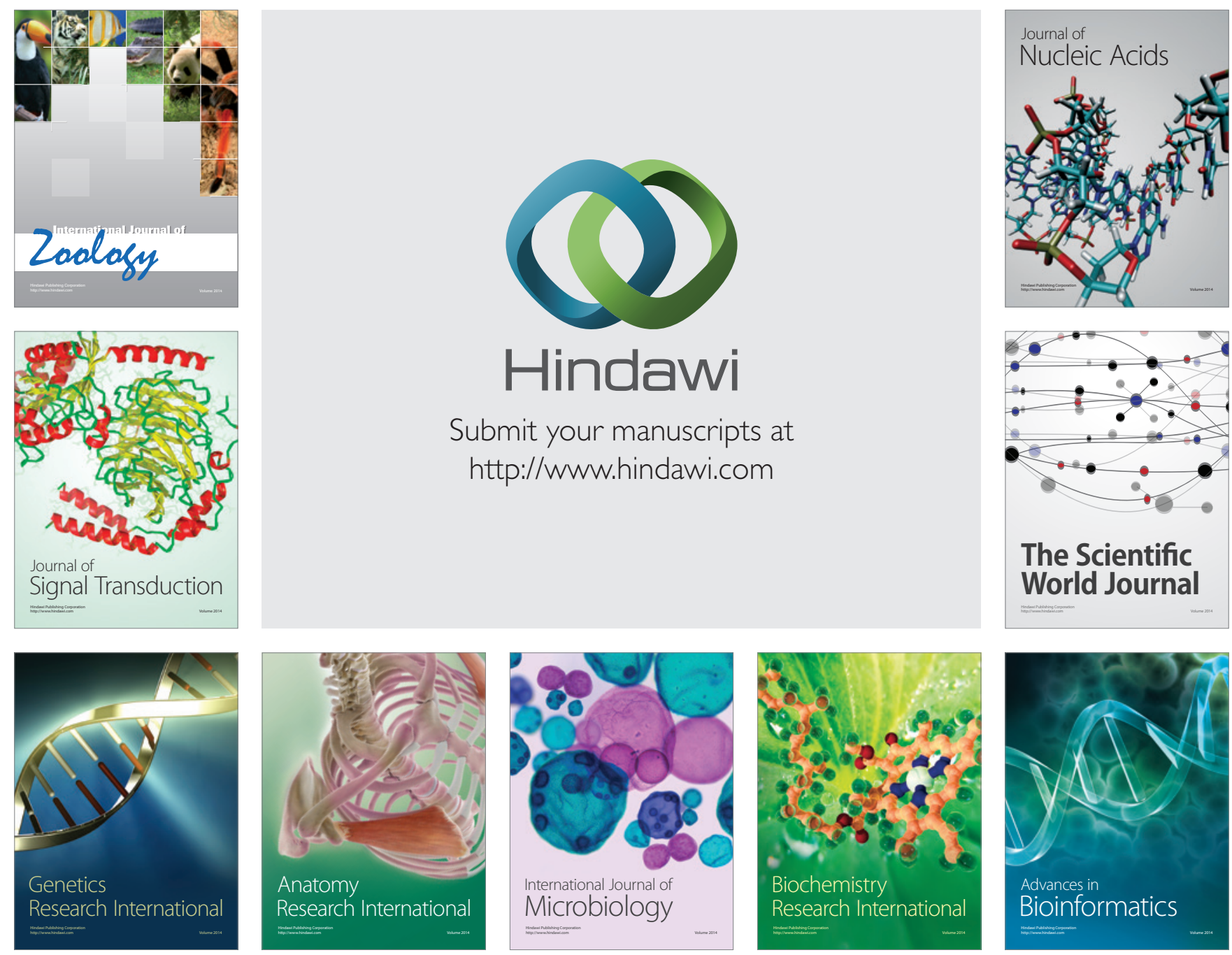

The Scientific World Journal
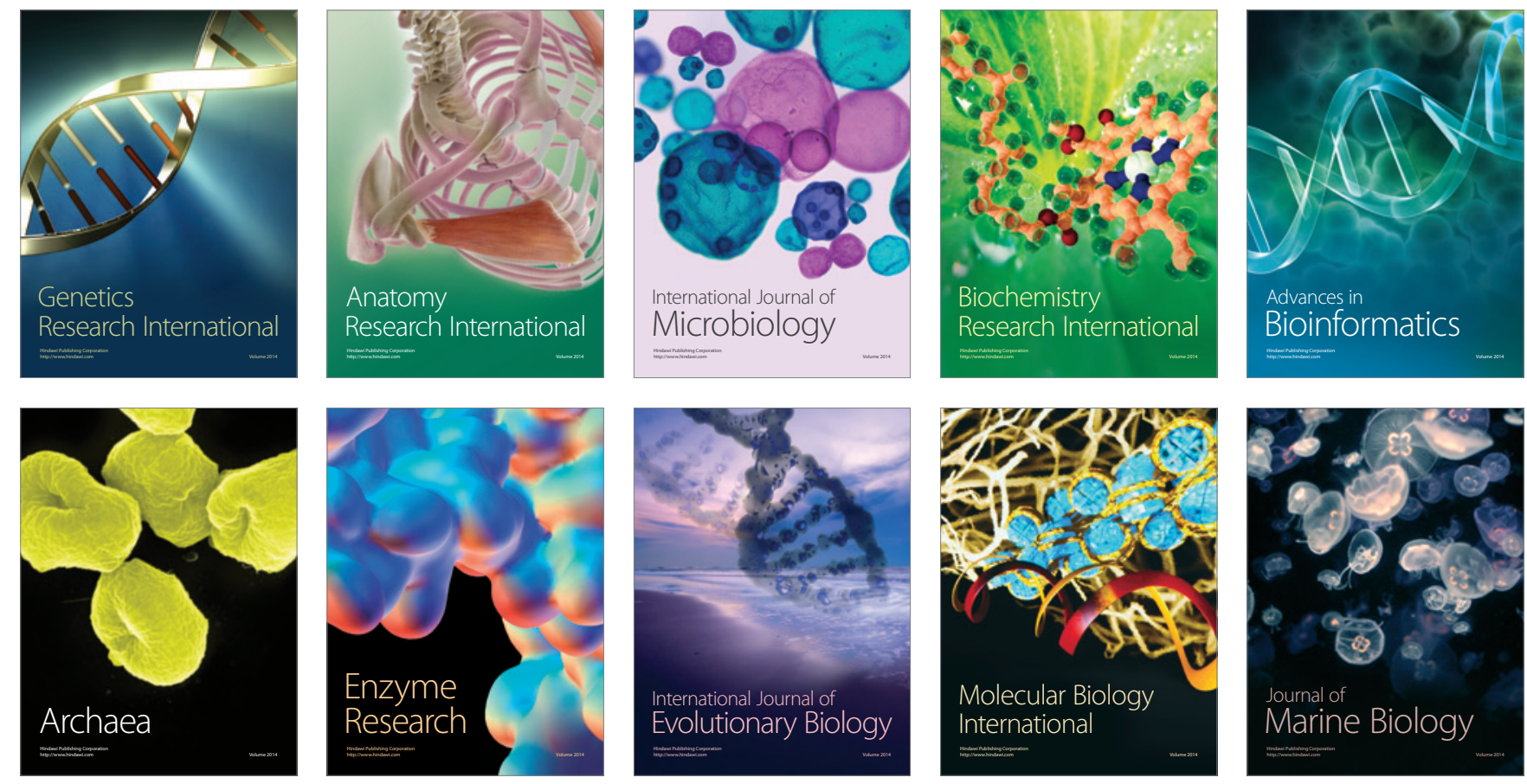